\title{
Water and Wastewater Pipe Nondestructive Evaluation and Health Monitoring: A Review
}

\author{
Piervincenzo Rizzo \\ Laboratory for NDE and SHM Studies, Department of Civil and Environmental Engineering, \\ University of Pittsburgh, 3700 O'Hara Street, 942 Benedum Hall, Pittsburgh, PA 15261-2294, USA \\ Correspondence should be addressed to Piervincenzo Rizzo, pir3@pitt.edu
}

Received 15 October 2009; Accepted 23 February 2010

Academic Editor: Jinying Zhu

Copyright ( 92010 Piervincenzo Rizzo. This is an open access article distributed under the Creative Commons Attribution License, which permits unrestricted use, distribution, and reproduction in any medium, provided the original work is properly cited.

Civil infrastructures such as bridges, buildings, and pipelines ensure society's economic and industrial prosperity. Specifically, pipe networks assure the transportation of primary commodities such as water, oil, and natural gas. The quantitative and early detection of defects in pipes is critical in order to avoid severe consequences. As a result of high-profile accidents and economic downturn, research and development in the area of pipeline inspection has focused mainly on gas and oil pipelines. Due to the low cost of water, the development of nondestructive inspection (NDI) and structural health monitoring (SHM) technologies for fresh water mains and sewers has received the least attention. Moreover, the technical challenges associated with the practical deployment of monitoring system demand synergistic interaction across several disciplines, which may limit the transition from laboratory to real structures. This paper presents an overview of the most used NDI/SHM technologies for freshwater pipes and sewers. The challenges that said infrastructures pose with respect to oil and natural gas pipeline networks will be discussed. Finally, the methodologies that can be translated into SHM approaches are highlighted.

\section{Introduction}

The soundness of engineering systems such as pipelines, railroads, highways, off-shore platforms, and other structural elements is essential to avoiding (or in order to avoid) catastrophic failures that may be accompanied by severe consequences for the environment, lead to the loss of human life, and produce tonnage of demolition waste. To design structures that are safe for public use, standardized building codes and design methodologies have been created. Unfortunately, structures are often subjected to harsh loading scenarios and severe environmental conditions not anticipated during the design process that will result in longterm structural deterioration [1].

Nondestructive evaluation (NDE) and structural health monitoring (SHM) techniques aim to assess the soundness of existing infrastructure. By preventing failures and detecting damage at an early stage, it may be indirectly inferred that the lifetime of these infrastructures can be expanded. NDE is usually conducted on a time basis by qualified personnel using commercially available technology. Conversely, SHM systems collect data from sensors, ideally mounted permanently on a given structure. The data are processed according to one of the many damage detection methods that have been proposed in the last two decades, as reported in $[2,3]$. In general, SHM can be defined as the process of implementing a damage identification strategy for engineering infrastructure. The damage identification process is generally thought to entail establishing: (i) the existence of damage, (ii) the damage locations, (iii) the types of damage, and (iv) the damage severity [4]. Depending upon the size, location, and operational condition of the engineering system under consideration, a reliable and permanent monitoring system can be very challenging. Therefore time-based approaches are more suitable. This is especially true for water and wastewater pipes that are buried.

In this review paper, we focus on both NDE and SHM methods that have been proposed in the last two decades to inspect or monitor freshwater mains and wastewater pipes. Driven by several high-profile accidents and economic downturn, research and development in the area of pipeline inspection have focused mainly on gas and oil pipelines. Due 
to the low cost of water and the technical challenges associated with the monitoring of buried pipes, the NDE/SHM of freshwater systems has received the least attention.

This paper provides a general guideline for those researchers interested in exploring and proposing new solutions to tackle the challenges associated with the inspection/monitoring of freshwater mains or wastewater pipelines.

\section{Motivation}

The economic and social costs associated with pipeline breaks in modern water supply systems are rapidly rising to unacceptably high levels. Many pipelines were installed in the first part of the 20th century and today are in poor condition and continue to deteriorate. The consequences of a pipeline break include direct costs (cost of repair, cost of water loss, cost of damage to surrounding infrastructure and property, liabilities), indirect costs (cost of supply interruption, cost of potentially increased deterioration rate of surrounding infrastructure and property, cost of decreased fire-fighting capacity), and social costs (cost of water quality degradation due to contaminant intrusion, cost of decrease in public trust and quality of water supply, cost of disruption of traffic and business, cost of disruption of water supply to special facilities) $[5,6]$.

In a recent document, the United States (U.S.) Environmental Protection Agency (EPA) reported that there are 240,000 water main breaks per year in the U.S. Large utility breaks in the Midwest increased from 250 per year to 2,200 per year during a 19-year period. Deficient water distribution systems cause, according to the U.S. Geological Survey, water loss of 1.7 trillion gallons per year at a national cost of $\$ 2.6$ billion dollars per year [7].

In Pittsburgh, Pennsylvania, two recent failures occurred in May 2009. A water main break left a $7.6 \mathrm{~m}$-wide hole in the roadway, prompting the Pittsburgh Water and Sewer Authority (PWSA) to shut down one street. PWSA discovered a $203.2 \mathrm{~mm}$ (8-inch) pipe broken which, in turn, caused a sewer to collapse [8]. The break had gone undetected for quite some time, allowing the underground hole to grow large enough to finally cause the roadway above to collapse. A few weeks later, a second break resulted in the closure of Route 88. Rushing water caused the pavement to buckle [9]. On September 2009, a 1.57 m (62-inch) water main broke in the Los Angeles area causing the closure of a road for three days, damaging nearby homes and businesses [10].

\section{Pipe Assets}

Pipes are one of the principal assets of a water supply system (WSS) and can be divided into transmission mains, distribution mains, and services. A variety of materials and technologies have been used in the production of water supply pipes. The material of a particular pipe depends on the year of installation and the diameter. For large transmission pipelines (with diameters over $300 \mathrm{~mm}$ ), steel, mild steel cement-lined (MSCL), or prestressed concrete

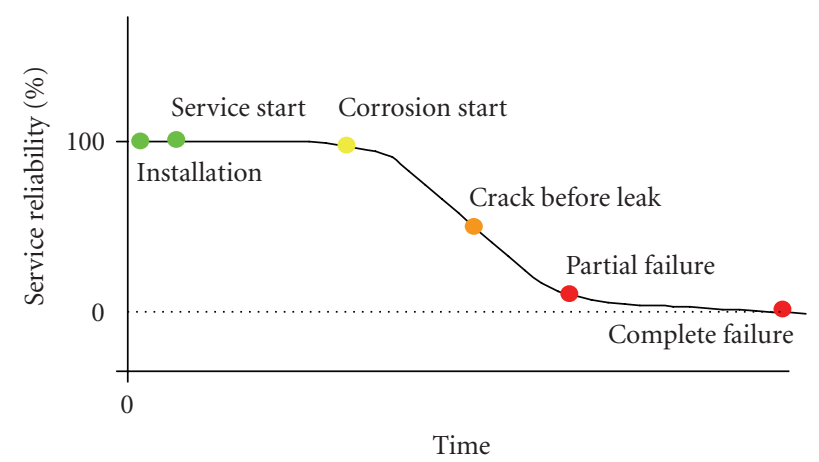

Figure 1: Pipe failure development. (Adapted from [6]).

cylindrical pipes (PCCPs) are typically used. Older waterdistribution mains are typically made of cast iron or asbestos cement, while mainly ductile iron and poly-vinyl chloride (PVC) are used for newer mains [6].

Pipe failure can be described as a multistep process as shown in Figure 1: installation, initiation of corrosion, crack before leak, partial failure, and complete failure. After the pipe has been in operation for some time, the corrosion processes start on the interior or exterior (or both) surfaces. These processes yield anomalies such as cracks, corrosion pits, and graphitization. In some cases cracks can be initiated by mechanical stress. None of them are severe enough to induce leaks. Developing corrosion pits or cracks reduces the residual strength of the pipe wall below the internal or external stresses, yielding pipe wall breaks and leaks. In some cases, this partial failure is not large enough to be readily detected. Finally, the complete failure of the pipe can be caused by a crack, corrosion pit, preexisting leak/burst, or a third-party interference. Failure is usually followed by water appearing on the ground surface or a considerable change in the hydraulic balance of the system [6].

Kleiner et al. [11] classified the deterioration of pipes into structural deterioration and internal deterioration. The first occurs when the pipe resiliency and the ability to withstand stress decrease. Internal deterioration occurs when the hydraulic capacity or the water quality diminishes, or severe internal corrosion appears. Structural deterioration mechanisms are affected by many factors including the type of pipe, its surrounding environment, and its operational conditions. Pipe breakage, with exception of situations in which it is caused by third-party interference, is likely to occur when the environmental and operational stresses act upon pipes whose structural integrity has been compromised by corrosion, degradation, inadequate installation, or manufacturing defects.

Asbestos cement and concrete pipes are subject to deterioration due to various chemical processes that either leach out the cement material or penetrate the concrete and form products that weaken the cement matrix. Quite often a pipe failure is caused by a combination of some form of damage or manufacturing flaw and applied external forces. PCCP fails when a sufficient number of loops of prestressing wire have broken in the same area. The wires normally break 
when corrosion activity has reduced their diameter to the point where the stress applied to them exceeds their yield point. This process may also cause damage to the mortar around the wires (allowing an acceleration of the corrosion process) or to the concrete inside the pipe [12].

Porosity is one of the most common manufacturing defects in cast iron pipes. Inclusions result in a discontinuity of the pipe material and may act as crack-formers. The variation in a pipe's wall thickness may lead to a situation where a part of the pipe's wall might no longer have a sufficient wall thickness for expected maximum pressures.

Pipe breakage types have been classified by O'day [13] into three main categories: circumferential cracking, longitudinal cracking, and bell splitting. In addition, Makar et al. [14] introduced the following failure modes: corrosion pitting and blow-out holes, bell shearing, and spiral cracking. Figure 2 depicts these different types of pipe-breaks.

\section{Pipe Inspection}

To date, two types of failure management strategies can be applied: proactive asset condition assessment and reactive failure detection and location. The former aims to prevent failure, the latter aims to minimize reaction time and losses associated with failure. However, as infrastructure ages, the price of water rises, the cost of materials increases, and pressure increases on public authorities to shift the management strategy from reactive to proactive.

Due to the different topology and hydraulic characteristics of the transmission (pipelines) and distribution (networks) components of a water supply system, separate failure detection and location techniques were proposed in the past. These techniques can be divided largely according to the physical phenomenon that they exploit: electromagnetic, mechanical, or visual. An extensive description of the principles, advantages, and limitations of each of the above technologies is beyond the scope of this paper. Interested readers may refer to some of the books in the area of NDE and SHM [15-19]. The performance and the feasibility of each technology are associated with their capability to gauge limited or large sections at once, and the need to interrupt service to allow for direct access.

The selection of the inspection method is mainly driven by the pipe's size and material. For instance, eddy currents (EC), electromagnetic testing (EMT), and ultrasonic testing (UT) are used in metal pipes. Acoustic emission (AE), impact-echo (IE), sonar, and visual inspection are used in concrete pipes. Some of these methods are implemented in pipeline inspection gauges (PIGs), which are computerized, self-contained devices inserted into the pipeline and propelled forward by the liquid flowing through the line, recording information as they go. PIGs were originally developed to remove deposits which could obstruct or retard flow through a pipeline [20].

As pointed out by Misiunas [6], in contrast with the oil and gas industries in which pipelines are already well instrumented and large investments in instrumentation are routine, the water distribution mains are usually poorly instrumented and the budget for water utilities does not allow a large investment for instrumentation. Therefore, most techniques were initially developed or applied to the oil or gas industry.

4.1. Acoustic Emission. AE is formally defined as the "release of transient elastic waves produced by a rapid redistribution of stress in a material" [21]. These waves are then detected by sensors such as piezoelectric transducers, hydrophones, or accelerometers. The actual source of the transient wave is a change within the material which is usually permanent and irreversible, such as the growth of a crack; so the AE method is suitable to detect damage onset and/or propagation, but cannot detect existing or "silent" damage. In PCCP and reinforced concrete pipes, $\mathrm{AE}$ is suitable to detect breaks of the steel reinforcement, crack onset, and propagation within the concrete. Other sources of emissions are friction, crack growth, turbulence, leak, and corrosion.

Travers [22] reported on the use of hydrophones to detect the sound caused by the failure and subsequent slippage of the reinforcing wire from PCCP. The work stemmed from the widespread corrosion and failure of the reinforcing wire on over 6 miles of 15-year-old pipes used in the Central Arizona Project in 1990. Initial field testing consisted of a single pair of hydrophones. Successively, there was the continuous monitoring of a 2-mile pipeline by means of an array of 12 hydrophones and a computer system to detect sounds in the pipeline, classify them as either wire-related sounds or extraneous sounds, and, based on the location of the wirerelated sounds, map areas of pipe deterioration.

Shehadeh and coauthors [23] proposed a linear array of sensors to locate and reconstitute the time-domain and frequency-domain signatures of AE sources in pipes. Simulated sources on sections of line pipe were used and a range of techniques, including a wavelet-transform technique, a cross-correlation technique, and a filtering and thresholding technique were proposed. The suitability of this approach in the field was not demonstrated.

The available, commercialized systems monitor the pipe using accelerometers, hydrophone arrays, or continuous fiber optic sensors. Following an acoustic event, the recorded signals are analyzed and compared to an existing database to determine the nature of the event. Monitoring PCCP by means of AE may not be very accurate because the method is restricted to detecting ongoing wire breaks, cannot detect already broken wires, and the monitoring period is short compared to the lifespan of the pipe [24].

4.2. Eddy Current. Pipe inspection methods by means of EC use a magnetic coil with alternating current to induce a time-varying magnetic field in the pipe. This magnetic field causes an electric current to be generated in the conducting material. These currents produce small magnetic fields around the material that generally oppose the original field and therefore change the impedance of the magnetic coil. By measuring the change in impedance of the magnetic coil as it traverses the sample, different pipes' characteristics can be identified. The method is restricted to those materials that are electrically conductive. In metal pipes, it has the potential to measure wall thickness and to detect discontinuities that 


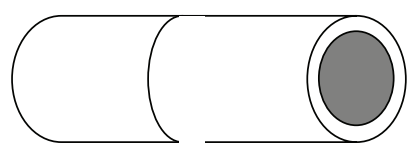

(a)

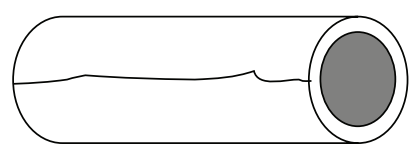

(b)

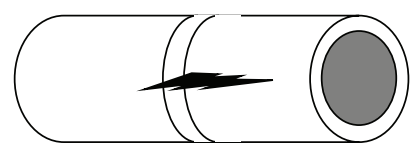

(c)

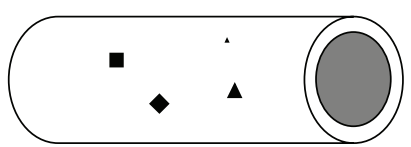

(d)

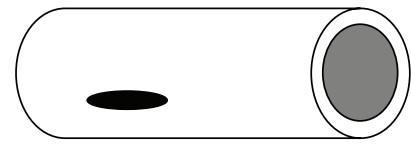

(e)

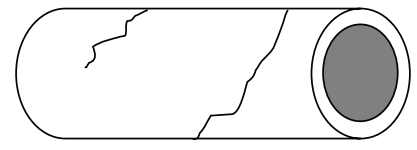

(f)

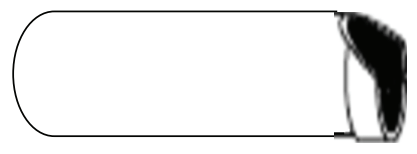

(g)

FIGURE 2: Different types of pipe breaks. Adapted from [6]. (a) Circumferential cracking; (b) Longitudinal cracking; (c) Bell splitting; (d) Corrosion pitting; (e) Blow-out hole; (f) Spiral cracking; (g) Bell shearing.

lie in plane transverse to the currents. Wall thickness in pipes as small as $100 \mathrm{~mm}$ (94 in.) can be assessed [20]. In reinforced concrete and PCCP, the method is valuable for the qualitative assessment of the steel reinforcement.

The main disadvantage of EC testing is the size of the skin depth, which is the depth of penetration of the alternating current. The skin depth sets the maximum depth to determine defects at a given frequency. To overcome this problem, the remote field eddy current (RFEC) method was proposed $[25,26]$. RFEC monopolizes on the existence of a secondary field that completely penetrates the wall thickness, allowing through-thickness inspection [16]. The current can travel along the outside of the pipe and be detected by far field coils, which are separated by approximately two times the pipe diameter from the excitation coils. This method relies on the fact that the remote field signal is larger than the direct eddy current signal measured by the detector coil [20].

The RFEC-based Hydroscope technology [27] consists of a train of sealed modules containing processing and transmission electronics. It is designed to traverse bends and tees, and is usually propelled through the pipe by water flow. Data is transferred by a wire line cable to the service vehicle. In an IRC evaluation [28], this technology was found to be able to locate and size corrosion pits of more than $3,600 \mathrm{~mm}^{3}$ in volume with an accuracy of $\pm 0.55 \mathrm{~m} \mathrm{[12].}$ Hydroscope Technology and Service claims the following practical advantages $[20,27]$ :

(i) detection of general wall loss, pitting, graphite corrosion,

(ii) equally sensitive to internal and external wall loss,

(iii) tests in either wet or dry pipes,

(iv) tests through lining and scale; extensive pipe cleaning not necessary,

(v) ease of access (through hydrant for 6 inches lines),

(vi) efficiency (up to 3,000 feet per day for typical lines),

(vii) $100 \%$ examination of pipe wall [20].

Another RFEC technology was reported by Jackson and Skabo [29] concerning a Ferroscope system developed by Cyberscope Industries Inc. and used by Russell NDE Systems,
Edmonton (Alberta) [20]. Two probes were pulled through the pipe, one scanning the entire circumference of the pipe for small defects, and the second with three sensors at $120^{\circ}$ spacing assessing the size of the damage. This method detected metal loss from $25 \%$ to $60 \%$ of the original pipe wall thickness. A thorough description of this remote field testing system is presented in [16].

Nestleroth and Davis [30] proposed an alternative approach to the common concentric coil method to induce low-frequency EC for pipes and tubes. Pairs of permanent magnets rotating around the central axis are used to induce high current densities in the material under inspection. Anomalies and wall thickness variations are detected with an array of sensors which measure local changes in the magnetic field produced by the current flowing in the material. A photo of their system is shown in Figure 3.

4.3. Electromagnetic Methods. EC testing is one of the methods based on electromagnetic principles. Other electromagnetic-based methods are ground penetrating radar (GPR) and short-pulse radar, which are the electromagnetic analog of sonic and ultrasonic pulseecho methods [31]. GPR uses electromagnetic radiation in the microwave band to detect reflected signals from subsurface structures. GPR can be used in a variety of media, including rock, soil, fresh water, pavements, and concrete. Microwaves are sent through materials of different dielectric constants to, for instance, inspect and locate buried objects, or assess rebar in reinforced concrete. Microwave inspection generally consists of measuring various properties of the electromagnetic waves scattered by, or transmitted through, a test article [32]. Transducers or antenna are used as transmitters and receivers.

In pipe applications, pipes can be measured from the ground surface or from the inside by moving the probing system along the pipe length. EM methods provide an accurate estimation of broken wires in some pipe segments. However, some results showed that the number of broken wires in PCCP can be either underestimated or overestimated $[24,33,34]$. Higher accuracy of results requires conducting calibration tests on test pipe sections to better understand the electromagnetic signal and determine the number of broken wires. These methods are not yet able to determine information on the concrete and data analysis and may 


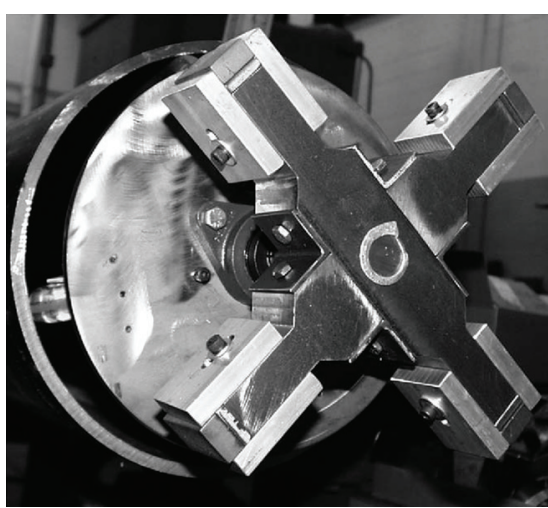

(a)

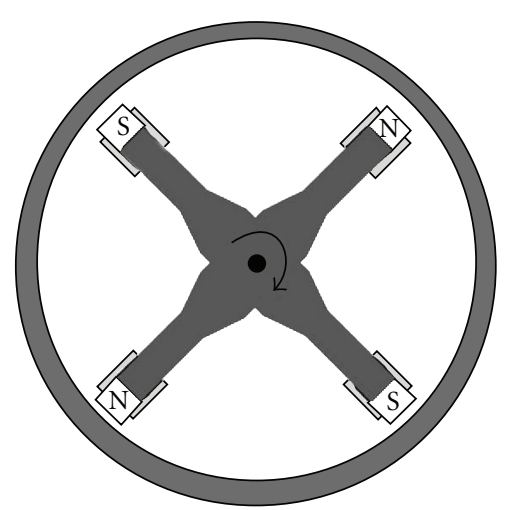

(b)

Figure 3: Photo of the eddy current system developed by Nestleroth and Davis (2007) [30]. Courtesy of Elsevier.

need to be carried out by experienced personnel. A second level of inspection for ferrous mains would be the use of electromagnetic methods to ascertain the amount of pitting, corrosion, or graphitization that has taken place.

Recently, in the Baltimore area, visual inspection, sounding, and electromagnetic testing were used for a pilot inspection program aimed toward assessing the condition of 17,000 feet of a 54-inch PCCP transmission main. The visual surveys consisted of measuring and checking each pipe for cracks and signs of structural distress. All cracks, circumferential and longitudinal, were noted and photographed. The internal EM probe senses electromagnetic anomalies caused by broken or deteriorated prestressing wires. The results were recorded on a small on-board data acquisition system. The data was subsequently analyzed and used to estimate the location and quantity of wire breaks $[34,35]$.

Remote Field Eddy Current/Transformer Coupling (RFEC/TC) and Polar wave (P-wave) are two commercially available systems that can provide information on the number of broken wires in PCCP. Both systems use moving platforms to conduct the survey from inside dewatered PCCP with an approximate speed of $1 \mathrm{~m} / \mathrm{s}$. The P-wave system consists of an emitter, which generates an electromagnetic field, and a receiver to catch the electromagnetic energy transmitted through the steel wires. The recorded signal shows distortion when a wire is broken, which allows for an estimation of the number of broken wires in the inspected pipe [24].

4.4. Impact-Echo. IE is a nondestructive method widely used in concrete structures to determine concrete thickness and detect delamination. The method exploits the propagation of stress pulses introduced into a test object by mechanical impact on the surface [36]. The method involves a simple signal processing technique that provides thickness, depth of delamination, and sound velocity inside the concrete, which in turn, is an indicator of the concrete's quality.

IE is feasible for PCCP and reinforced concrete pipes. It allows for the detection of delaminations and cracks in various concrete/mortar/steel interfaces. The method requires dewatering and human access to the pipes' interiors, but it can be done externally if exterior access is available. Although IE was successfully applied to concrete structures, its use to inspect PCCP presented some difficulties [24]:

(1) the method yields to indications, which are not necessarily related to features that reduce the structural integrity of the pipe [37];

(2) it is difficult to detect problems in the mortar coating of the pipe [37];

(3) the method is not yet automated to inspect the entire pipe surface with reasonable speed. Carino [36] stated that the method yields indications, which are not necessarily related to features that reduce the structural integrity of the pipe.

4.5. Hammer Sounding. Similar to impact-echo, hammer sounding inspection is the basic, first, and most used method to inspect PCCP [24]. It is conducted by using a hammer or rod to strike either the outside of an uncovered in-service pipe, or the inside of a pipe which however needs to be taken out of service to allow a crew's entry. The hammer sounding aims to detect a "hollow sound" area, which is often associated with the detachment of the steel cylinder from the concrete core and delamination of the outside mortar coating. External observations include degradation of the mortar coating, longitudinal and/or circumferential cracks in the mortar coating, spalling, broken wires, corroded wires, corroded steel cylinder, rust stains, longitudinal cracks, circumferential cracks, and efflorescence. Internal observations include longitudinal and circumferential cracks in the concrete core, stains, construction, and previous repair errors and joint problems.

4.6. Leak Detectors and Transient Analysis. Acoustic leak detectors (ALD) and transient analysis are passive approaches to detect leaks in pipelines. ALD systems consist of listening devices attached to the pipes or appurtenances to detect leak-induced sound. Traditional techniques have relied on the detection of leakage from above ground using accelerometers or hydrophones attached at strategic locations [38]. Ground microphones can also be used to listen and pinpoint leaks by listening on the pavement surface or soil directly above the pipe [39]. The water 
service department of the city of Bristol, UK, studied the performance of acoustic noise loggers for leak location in water networks. The study found that acoustic loggers underperformed when compared to a professional leakage inspector [40]. Recently noise loggers were integrated with amplifiers and noise filters to enhance the signal-tonoise ratio. The effectiveness of ALD methods has been successfully demonstrated for metallic pipes [41, 42] and plastic pipes [43]. A detailed review of ALD methods is presented in [44].

In ALD systems, the most common technique of leak location is the cross-correlation. Measured vibrations or acoustic signals from two receivers are transmitted to the leak noise correlator, which computes a cross-correlation function of the two signals. If a leak is present between the sensors, the cross-correlation function will have a distinct peak. A corresponding time delay indicates the difference in arrival times of the leak noise signals at each sensor and is related to the location of the sensors. By knowing the acoustic speed in water, the leak location can be pinpointed $[6,39]$. Cross-correlation testing results are presented in $[43,45]$.

Sahara (Figure 4) is a pigging technology based on ALD principles. A sensor mounted on an umbilical cable is introduced into the pipe and a small parachute uses the flow of water to draw the sensor through the pipeline. As the sensor passes any leak it detects the sound generated and gives an indication to the operator. The umbilical cable allows its position along the pipe to be controlled [46, 47].

Methods based on transient analysis measure water pressure, hydraulic characteristics, and use back calculation (inverse analysis) to detect and locate leaks. The methods rely upon the fact that a sudden pipe break creates a negative pressure wave that travels in both directions away from the breaking point and is reflected at the pipeline boundaries. Using the pressure data measured at one location along the pipeline, the timing of the initial and reflected transient waves induced by the break determines the location of the break. The magnitude of the transient wave provides an estimate of the break size. The method can be enhanced by using advanced pattern recognition systems and/or signal processing techniques such as genetic algorithms \linebreak $[48,49]$.

Misiunas and coauthorsauthors [5] proposed a continuous monitoring approach for detecting and locating breaks in pipelines. The continuous monitoring technique was verified by using results from both laboratory and field experiments, and showed potential for detecting and locating sudden breaks in real pipelines.

Karney et al. [39] reported on the use of inverse transient analysis on an initial simulation phase of a study which aimed to assess the applicability and effectiveness of inverse transient analysis to the detection of leaks in real water distribution systems. Simulation was conducted on various scenarios of transient severity and leak sizes. As summarized by Misiunas [6], limited experiences from laboratory and field tests $[50,51]$ include single pipe cases in which a controlled transient is introduced to detect and locate a leak. The challenge for field application is the need to possess an accurate modeling of the transients and boundary conditions of the pipe system. Colombo and coauthorsauthors [52] offer a selective literature review of transient-based leak detection methods. While not exhaustive, numerous publications are cited in an attempt to provide a reasonable cross-section of research activity and the various methodologies. The review shows that field work and verification of these techniques are still generally lacking.

4.7. Magnetic Flux Leakage. MFL consists of magnetizing a test part, generally a ferromagnetic material, and scanning its surface with some form of a flux-sensitive sensor [19]. The magnetic lines of force (or flux) flow through the material and complete a magnetic path between the pole pieces. When the flux is contained within the test piece, its detection in the air space surrounding the object is very difficult. However, if a structural anomaly disrupts the surface of the magnetized structure, the permeability is changed and leakage flux will emanate from the discontinuity [53]. Defects are therefore detected by measuring changes in the pipe's magnetic permeability.

In pipe inspection, MFL is assembled into pigs carrying permanent magnets or electro-magnets that generate magnetic flux in the pipe so that the field travels in the same direction as the pipe axis. This method is feasible for buried or surface cast iron and steel pipes to detect metal loss associated with corrosion and to detect circumferential and longitudinal cracks. In areas where there is corrosion or metal loss, the pipe wall thickness is reduced, which leads to the decrease in the amount of magnetic flux compared with that carried in a full thickness wall. That means that magnetic flux leaks when defects occur on the pipe's surface. The leakage of magnetic flux can be measured by sensors located inside the pipe $[12,20,54-56]$. The leakage depends on the physical size of the pipe, the magnetic characteristics of the pipe and nearby materials, the stresses in pipelines, and the shapes and dimensions of the defects. MFL may have limited performance to detect cracks, including axial stress corrosion cracks and seam weld cracks, because they are extremely shallow, long, or narrow [57]. Lijan et al. [58] claimed that aMFL tool can move through the pipes at a speed of 0.7 to $4 \mathrm{~m} / \mathrm{s}$ with test runs of at least $100 \mathrm{~km}$. The level of magnetization is a key factor in providing reliable and accurate inspection results [20].

Since 1965, when Tuboscope introduced the first MFL inline inspection tool for pipelines, MFL has been increasingly employed in the pipeline industry. MFL inspection in water pipes requires close contact between the pig and the pipe wall. Makar and Chagnon [12] stated that the use of MFL tools in the water industry is limited to cleaned, unlined pipes. Generally, four types of MFL tools are available to be chosen from according to different testing levels of sensitivity. They are Standard or Low-Resolution tools, High Resolution (High-Res) tools, Extra High-Resolution (XHR) tools, or The XHR "newest generation" systems. The four MFL tools mainly differ in the resolution or the accuracy of the data collection by changing the size and spacing (number) of sensors [59].

As for many other NDE/SHM techniques, the use of advanced signal processing is pivotal to improve the 


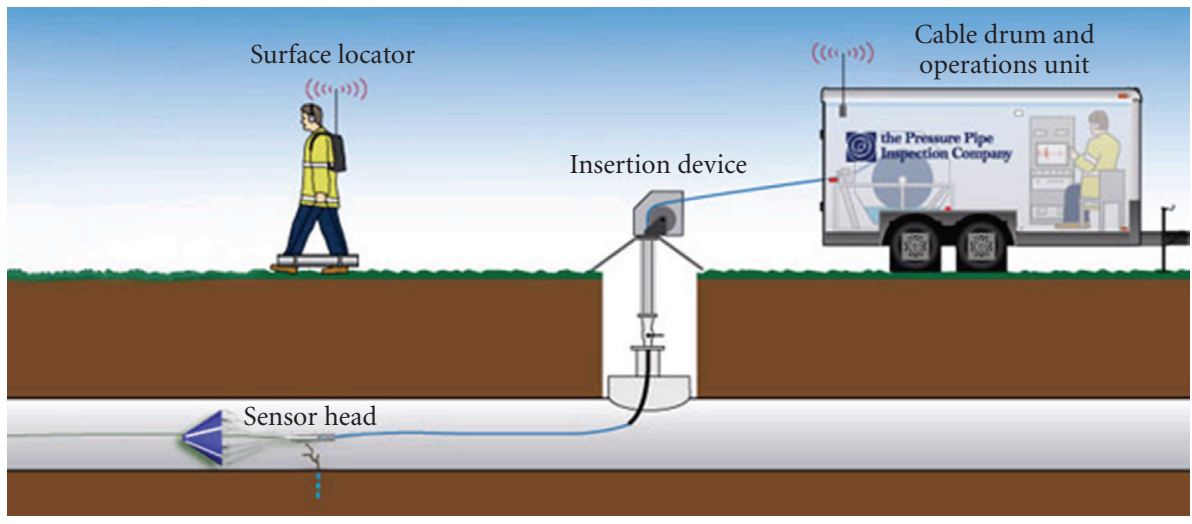

Figure 4: The Sahara system 46. Image Courtesy of the Pressure Pipe Inspection Company.

performance of MFL systems as well. Mukhopadhyay and Srivastava [55] suggested the use of a discrete wavelet transform for denoising MFL signals and for the classification of defects. Joshi et al. [60] proposed a method on adaptive wavelets and radial basis function neural network (RBFNN). They used a new approach of iterative inversion using a multiresolution wavelet transform to predict 3D defect geometry from MFL measurements obtained from a gas transmission pipeline inspection.

4.8. Sonar. Sonar measures the time it takes for a burst of sound to travel from a source to a target and back again. By knowing the velocity of sound through the appropriate medium, the distance from the source to the target can be determined. Sonar is mainly used in wastewater management to provide pictorial evidence of sewers beneath the flow line. Sonar can generate a 360-degree outline of the interior of a fill pipe, or the outline of the wetted area only, and is suitable to "see" the surface profile. Sonar can be operated in air or water but it cannot be operated in both air and water simultaneously. Consequently, only the part of the pipe above the water line, or conversely the part of the pipe below the waterline, can be assessed $[20,38,61]$. In Section 4.9, systems that combine Sonar-based technologies and closedcircuit television (CCTV) will be discussed.

4.9. Ultrasonic Testing. Methods based on the propagation of ultrasonic stress waves use one or more probes to send broadband or narrowband mechanical waves through a medium. Conventional UT, such as local thickness gauging, use bulk waves to test a limited region within the ultrasonic probe. Such approaches may be time consuming when applied to large structures. A commercial system based on ultrasonic Bscan and C-scan is the UltraScan CD inspection tool [62]. The CD tool directs ultrasonic waves circumferentially into the pipe wall at an angle that generates $45^{\circ}$ shear-waves within the metal. The transducers are mounted on a flexible carriage at the rear of the tool. With large numbers of transducers generating pulses and receiving their reflections, as many as ten simultaneous readings can be taken from each flaw or pipeline feature.
Whenever an ultrasound propagates into a bounded media, a guided ultrasonic wave (GUW) is generated. The wave is termed "guided" because it travels along the medium guided by the medium's geometric boundaries. GUWs propagate along, rather than across, the waveguide. In pipe applications, GUWs may propagate along the pipe's longitudinal direction and excite the entire cross-section $[19,63,64]$, and therefore GUWs are effective when large inspection coverage is required. The advantage of GUW inspection is its ability to probe long lengths of the pipe, locating cracks and notches from few monitoring points, while providing full coverage of the pipe's cross-section [63-66]. In addition, by combining the methodology with opportune signal processing, the method is feasible for the permanent monitoring of the pipe's health.

The ability of guided waves to locate cracks and notches in pipes has been demonstrated in several laboratory works $[63,66-69]$. One of the advantages of GUWs in pipelines is that the theoretical foundation of wave propagation is well formulated (see, e.g., [19]). In addition, numerical methods, such as the DISPERSE package developed by the Imperial College in the U.K. [70], have been developed for extracting modal solutions from a variety of waveguides, including empty and filled pipes. Another numerical method is the 2D Finite Element Method, or Semi-analytical Finite Element (SAFE) Method, which can model waveguides of arbitrary cross-sections by simply discretizing a bidimensional domain [71-73].

Gauthier et al. [74] reported on an ultrasonic wave inspection technique using horizontally polarized shear waves. These waves can follow curvature and thus enable inspection along bends and other irregular geometric shapes. They tested steel pipe samples and found that shallow cracks larger than $10 \%$ of the wall thickness could be detected. Demma and coauthorsauthors [75] studied experimentally and numerically the reflection of the torsional $\mathrm{T}(0,1)$ guided mode from defects in pipes in the frequency range 10$300 \mathrm{kHz}$. Both crack-like defects with zero axial extent and notches with varying axial extents were considered. The results showed that the reflection coefficient from axisymmetric cracks increases monotonically with depth at all frequencies, and increases with frequency at any given depth. 
With nonaxisymmetric cracks, the reflection coefficient is a roughly linear function of the circumferential extent of the defect at relatively high frequencies, the reflection coefficient at low circumferential extents falling below the linear prediction at lower frequencies. With nonaxisymmetric defects, mode conversion to the flexural $\mathrm{F}(1,2)$ mode was seen, and at lower frequencies the flexural $\mathrm{F}(1,3)$ mode was also produced.

Field applications of GUWs were recently reported. Ledesma et al. [76] presented a case study of the guided wave testing of a nonpiggable gas transmission pipeline of an approximate length of $1 \mathrm{~km}$. The pipeline was partially above ground and partially underwater or buried in soil. They used equipment developed by Guided Ultrasonics, Ltd [77]. Vinogradov [78] verified the capability of magnetostrictive transducers to generate GUWs to screen an empty buried pipe mockup. The study did not include in-service water pipes. Sun et al. [79] and coauthorsauthors used the propagation of longitudinal wave $\mathrm{L}(0,2)$ to screen a 40 meter-long heating pipe in the residential area of the Bohai Oil Company in Tianjin city, China. Factors, such as the number of transducers and transducer ring spacing, were discussed.

Ultrasonic methods for PCCP inspection make use of an ultrasonic pulser in the pipe wall and analyze recorded time and frequency pulses' characteristics (using an array of sensors placed near the source) to determine the possibility of wire breakage. The test can be conducted either from the inside dewatered pipe or from the outside in-service pipe. Velocity and frequency of pipe resonance are measured to determine the concrete quality and detect delamination and/or cracks. Even though the Sonic/Ultrasonic method provides information on concrete, its accuracy in detecting broken wires is not yet clear. The method appears to be good for testing selected uncovered PCCP sections from the outside [24]. As concrete is more attenuative than metals, the area inspected by conventional UT or GUWs is smaller compared to metal pipes. In addition, the ultrasonic frequencies used must be lower.

4.10. Visual Inspection. Visual methods are related to the use of closed-circuit television (CCTV). This is the standard technology for the NDE of the internal condition of sewers and storm water pipes [47]. The CCTV technique involves the use of a robot-mounted forward-looking pan/tilt and zoom camera and lighting system mounted on a wheeled carriage that travels between two manholes. CCTV equipment is operated by certified operators who are trained to control the camera and interpret video streams. CCTV can identify defects such as longitudinal/circumferential cracks, fractures, deformation, collapse, breaks, open or displaced joints, surface abrasion or corrosion, tree root penetration, encrustation, and lateral connections. Each sewer is rated based on the number and severity of defects. The defect codes are then assigned scores based on their severity. These scores are then used to calculate the total, peak, and mean scores. Based on these scores, a condition grade is calculated on a $1-5$ scale [80]. New advances in digitizing the video stream have made this tool more users-friendly. CCTV still

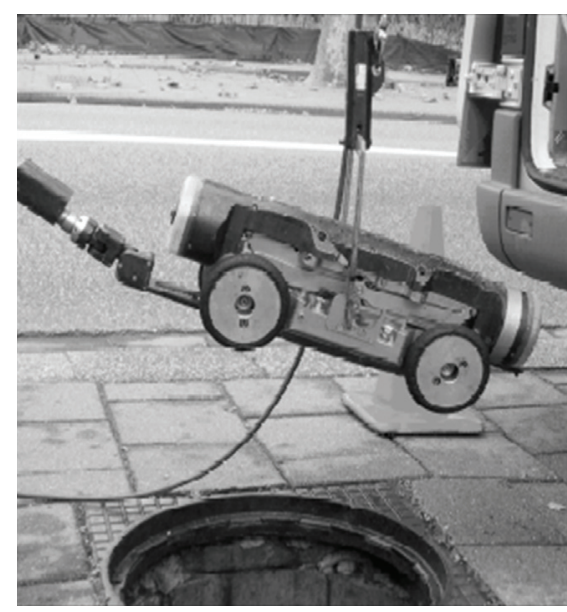

FIGURE 5: The PANORAMO system. (Source: http://www.werf.org/ AM/CustomSource/Downloads/uGetExecutiveSummary.cfm?FILEES-01-CTS-7.pdf\&ContentFileID=1960. Courtesy of WERF.

requires an operator's subjective interpretation of observed defects and is limited to the pipe surface located above the flow surface. Moreover, CCTV is mainly qualitative in nature. Recently, software in support of the operator has been developed like AQUA-selekt, AQUA-WertMin [81], or other image processing techniques. CCTV systems are capable of (1) detecting anomalies along the interior wall surface, (2) storing large amount of images, and (3) providing a pictorial view of the structure. CCTV has come a long way since then and is now the dominant force in state-of-the-art inspections receiving widespread use within the industry [20].

Systems like the Panoramo 3D shown in Figure 5 mount optical scanners which provide the same information as digital CCTV, with the added benefit of being able to unwrap the pipe size. The cost for this level of inspection is nearly the same as CCTV, but it does have the benefit of providing a measurable analysis.

Sarshar and coauthors [80] described the development of a software system to semiautomatically extract historical condition data information from archived sewer inspection CCTV files. The software was used to access, analyze, and evaluate sewer condition data from CCTV video files and particularly to automate the detection of other types of defects, for example, excessive debris, penetrating roots, and displaced joints. Images from the City of Regina in Canada were analyzed. The use of image-processing techniques for automated identification of cracks in sewer pipes has been studied $[82,83]$.

Systems combining CCTV and sonar, mounted one above the other, were recently proposed to survey pipes above the waterline (by means of CCTV) and below the waterline (by means of sonar). An example of such a system is the cable-guided swimming system (SEK) which was developed in Germany to inspect wastewater mains and is shown in Figure 6. SEK allows sewer operators to inspect freegradient sewers with large diameters which, because of their filling levels, are normally inaccessible (e.g., before treatment plants) [84]. The strategy includes a three-stage approach. In 


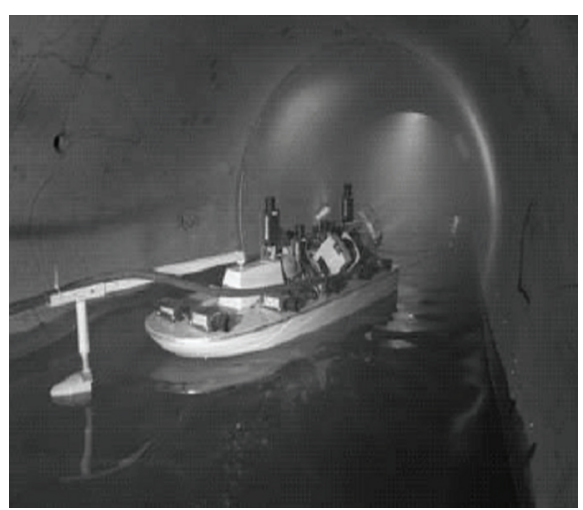

(a)

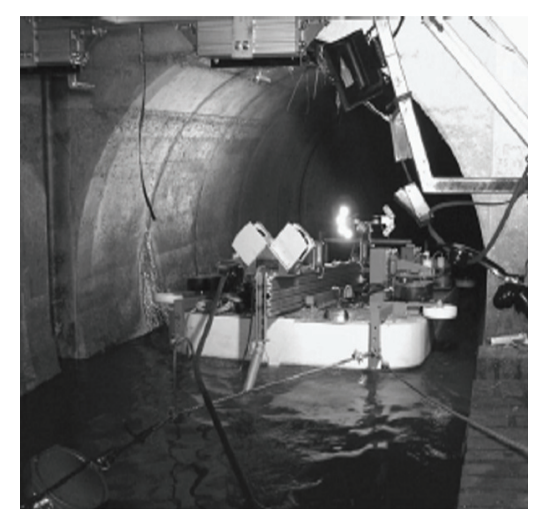

(b)

FIGURE 6: (a) SEK prototype; (b) SVM. Photos from [84]. Courtesy of IWA Publishing.

the first stage, SEK is employed in the sewer for inspection. It inspects and measures the entire sewer line and conducts camera inspections, recording major abnormalities such as erosion, deposits, obstacles, and leaks in the gas space. At the same time, it checks whether the cleaning and inspection systems detailed below can be deployed. An SEK is able to center itself even in curved pipes in the sewer covering a length of $600 \mathrm{~m}$. In the second stage, the wheel-driven cleaning device eliminates deposits detected by the SEK in the bed area and cleans the sewer wall before the inspection system is deployed. In the third stage, aSVM (damage survey device) system surveys the sewer completely, measuring joint widths, pipe offsets, and cracks with greater accuracy than the SEK. An SEK is equipped with several flashlights for illumination. In contrast to the SEK, the SVM achieves greater accuracy. It is carried by (1) floating systems for large sewer diameters and (2) wheeled chassis for smaller sewer diameters. The floating systems are limited by the required water level. Wheel-guided car systems are used when the filling level is low or when the nominal diameters are smaller. Sensors for determining the position in the sewer (laser ranging sensors and inclination sensors) and sensors for damage surveys (laser scanners, ultrasound scanners, camera system, ultrasound crack sensor) are installed on the SVM. Ultrasound scanners, laser scanners, and camera systems are mounted on a linear axis and can precisely measure the pipe profile over a length of approximately 1.5 meters.
The Sewer Scanner and Evaluation Technology (SSET) developed by TOA Grout, CORE Corp., and the Tokyo Metropolitan Government's Sewer Service (TGS) Company utilizes optical scanner and gyroscope technology, in addition to standard CCTV technology [85, 86]. Survey speed for the SSET is reported as $60 \mathrm{~m} /$ hour. The SSET system has been evaluated through the Civil Engineering Innovative Technology Evaluation Centre, an innovation center within the American Society of Civil Engineers (ASCE), Civil Engineering Research Foundation (CERF). The evaluation included field demonstrations performed at thirteen municipal public works agencies throughout North America. The evaluation assessed the functional performance, constructability/practicality, maintainability, safety, and environmental characteristics [20]. Advantages of SSET include its ability to produce a digital record of the pipe, to identify vertical deflection in pipes, and to deliver easily comprehensible and manageable results. The main disadvantages of the SSET include its inability to see into laterals or to operate in dark-colored pipes. A full evaluation report was released in 2001 [87].

4.11. Other. As for the SEK-SVM and SSET systems described in the previous section, there are few other systems that carry multiple technologies to assess wastewater pipes: the Sewer Assessment by Multi-Sensors (SAM) funded by the German Research Foundation and the Pipe Inspection Real-time Assessment Technique (PIRAT) developed by Melbourne Water and CSIRO and funded by the Australia's research agency are multisensor systems. The SAM platform includes [88]

(i) a commercial CCTV system in addition to optical triangulation which permits optical 3D measurement of the pipe shape (diameter and deviations from ovality),

(ii) a microwave, rotatable sensor to inspect the soil state behind sewerage pipes,

(iii) a geoelectrical sensor for the identification of leak points,

(iv) hydrochemical sensors for the detection of groundwater infiltration,

(v) radioactive sensors to detect sewer leaks, holes behind sewer pipes, and small orifices in water mains,

(vi) acoustic systems suitable for detecting cracks and determining the state of connections and pipe bending.

PIRAT $[89,90]$ was developed to detect, classify, and rate defects using artificial intelligence by building a cylindricalpolar geometric model of the interior of the sewer using a scanner (laser or sonar) carried by a robotic in-pipe vehicle. The vehicle carries the scanner along the centerline of the sewer and has a forward-facing color video camera, lighting, and other sensors. 


\section{Discussion and Conclusions}

This paper provides an agile and general review of the most used NDE techniques for the inspection and monitoring of water mains and wastewater networks. The attention has mainly focused on electromagnetic methods such as eddy current, ground penetrating radar, and magnetic flux leakage, mechanical methods such as acoustic emission, ultrasonic testing, impact-echo, acoustic leak detection, and sonar, and visual inspection methods based on the use of closed-circuit cameras. For each method the main advantages and principles and its mode of employment in freshwater and wastewater pipes were discussed. A few representative works conducted in academia and in the private sector have been reviewed. The latter focused on inspection tools deployed and tested in the field. A distinction in terms of needs and challenges between metal and concrete pipes has been made. Finally, a few case studies are reported. Interested readers may refer to [91] for a review on fourteen case studies conducted at different water municipalities worldwide.

All systems discussed here present many advantages but also carry some limitations as well. The inspection of wastewater pipes by means of CCTV, laser scanning, or sonar can be improved by enhancing the image resolution of CCTV but still the methods are limited to the detection of surface anomalies. The development of automatic image processing will make the analysis of long and tedious images less prone to the subjective evaluation of the inspectors.

The periodic inspection or the permanent monitoring of freshwater mains or distribution pipes may be greatly benefited by a trenchless untethered system that can probe the structures from the inside without service interruption. Such a system would definitely bring a technological leap in the area of water pipe inspection. None of the methods discussed in this review paper seems to satisfy such ideal technologies. Electromagnetic methods or stress waves-based methods either require the structure temporarily out of service to inspect from the inside or require excavation in order to conduct the inspection from the outside. Acoustic leak detectors are promising if the technology can become untethered. However, these detectors are not suitable to detect anomalies that have not yet deteriorated into leaks. Finally, as for any structural health monitoring strategy, pipe health monitoring includes other importance issues, such as modeling of damages, establishing criteria, or setting up indices for damage evaluation. These aspects were not discussed here as beyond the scope of the present paper.

\section{References}

[1] J. P. Lynch and K. J. Loh, "A summary review of wireless sensors and sensor networks for structural health monitoring," The Shock and Vibration Digest, vol. 38, no. 2, pp. 91-128, 2006.

[2] S. W. Doebling, C. R. Farrar, and M. B. Prime, "A summary review of vibration-based damage identification methods," Shock and Vibration Digest, vol. 30, no. 2, pp. 91-105, 1998.
[3] H. Sohn, C. R. Farrar, F. M. Hemez, et al., "A review of structural health monitoring literature: 1996-2001," Tech. Rep. LA-13976-MS, Los Alamos National Laboratory, Los Alamos, NM, USA, 2004.

[4] K. Worden, C. R. Farrar, G. Manson, and G. Park, "The fundamental axioms of structural health monitoring," Proceedings of the Royal Society A, vol. 463, no. 2082, pp. 1639-1664, 2007.

[5] D. Misiunas, J. Vítkovský, G. Olsson, A. Simpson, and M. Lambert, "Pipeline break detection using pressure transient monitoring," Journal of Water Resources Planning and Management, vol. 131, no. 4, pp. 316-325, 2005.

[6] D. Misiunas, Failure monitoring and asset condition assessment in water supply systems, Ph.D. dissertation, Lund University, Lund, Sweden, 2005.

[7] US Environmental Protection Agency, "Addressing the challenge through innovation," 2007, http://www.epa.gov/ nrmrl/pubs/600f07015/600f07015.pdf.

[8] "Sewer collapse closes chateau street on north side," May 2009, http://www.post-gazette.com/pg/09134/970143-100.stm.

[9] “Water main break closes Route 88," May 2009, http://www .post-gazette.com/pg/09146/972733-100.stm.

[10] http://latimesblogs.latimes.com/lanow/2009/09/coldwatercanyon - could - be - closed - for - 3 - days - due - to - destructive water-main-break.html.

[11] Y. Kleiner, B. J. Adams, and J. S. Rogers, "Water distribution network renewal planning," Journal of Computing in Civil Engineering, vol. 15, no. 1, pp. 15-26, 2001.

[12] J. Makar and N. Chagnon, "Inspecting systems for leaks, pits, and corrosion," Journal of American Water Works Association, vol. 91, no. 7, pp. 36-46, 1999.

[13] D. O'day, "Organizing and analyzing leak and break data for making main replacement decisions," Journal of American Water Works Association, vol. 74, no. 11, pp. 588-594, 1982.

[14] J. Makar, R. Desnoyers, and S. McDonald, "Failure modes and mechanisms in gray cast iron pipe," in Underground Infrastructure Research: Municipal, Industrial and Environmental Applications, M. Knight and N. Thomson, Eds., pp. 303-310, Swets \& Zeitlinger, Lisse, The Netherlands, 2001.

[15] D. E. Adams, Health Monitoring of Structural Materials and Components, John Wiley \& Sons, London, UK, 2007.

[16] P. J. Shull, Nondestructive Evaluation: Theory, Techniques, and Applications, Marcel Dekker, New York, NY, USA, 2002.

[17] J. L. Rose, Ultrasonic Waves in Solid Media, Cambridge University Press, Cambridge, UK, 1999.

[18] J. D. Achenbach, Wave Propagation in Elastic Solids, NorthHolland, New York, NY, USA, 1984.

[19] D. E. Bray and R. K. Stanley, Nondestructive Evaluation. A Tool in Design, Manufacturing, and Service, CRC Press, Boca Raton, Fla, USA, 1997.

[20] Trenchless Technology Network, Underground Mapping, Pipeline Location Technology and Condition Assessment, Infrastructure Engineering and Management Research Centre, The University of Birmingham, 2002.

[21] W. Prosser, "Acoustic emission," in Nondestructive Evaluation: Theory, Techniques, and Applications, P. J. Shull, Ed., Marcel Dekker, New York, NY, USA, 2002.

[22] F. A. Travers, "Acoustic monitoring of prestressed concrete pipe," Construction and Building Materials, vol. 11, no. 3, pp. 175-187, 1997.

[23] M. Shehadeh, J. A. Steel, and R. L. Reuben, "Acoustic emission source location for steel pipe and pipeline applications: the role of arrival time estimation," Journal of Process Mechanical Engineering, vol. 220, no. 2, pp. 121-133, 2006. 
[24] R. Al Wardany, "Condition assessment of prestressed concrete cylindrical water pipes," in Proceedings of the 60th Annual WCWWA Conference and Trade Show, Regina, Canada, September 2008, NRCC-50562, Protecting Our Water.

[25] E. R. MacClean, US patent 2,573,799, November 1951.

[26] T. R. Schmidt, D. L. Atherton, and S. Sullivan, "Use of onedimensional skin-effect equations for predicting remotefield characteristics, including wall-thickness versus frequency requirements," Materials Evaluation, vol. 47, no. 1, pp. 76-79, 1989.

[27] http://www.picacorp.com/.

[28] J. Makar and S. Mcdonald, "Assessment of the hydroscope 201TM condition index evaluation of gray cast iron pipe from gatineau," Tech. Rep. QUEBEC NRC REPORT A-7015.3, National Research Council, Ottawa, Canada, 1996.

[29] R. Z. Jackson and R. Skabo, "Nondestructive testing of water mains for physical integrity," American Water Works Association (AWWA) Research Foundation, 1992, http:// www . waterresearchfoundation.org/research/TopicsAndProjects/projectSnapshot.aspx?pn=507.

[30] J. B. Nestleroth and R. J. Davis, "Application of eddy currents induced by permanent magnets for pipeline inspection," NDT \& E International, vol. 40, no. 1, pp. 77-84, 2007.

[31] G. C. Clemena, Short-Pulse Radar Methods in Handbook of Nondestructive Testing of Concrete, V. H. Malhotra and N. J. Carino Ed., CRC Press, Boca Raton, Fla, USA, 2004.

[32] A. J. Bahr, R. Zoughi, and N. Qaddoumi,, "Microwave," in Nondestructive Evaluation: Theory, Techniques, and Applications, P. J. Shull, Ed., Marcel Dekker, New York, NY, USA, 2002.

[33] B. Mergelas and X. Kong, Electromagnetic Inspection of Prestressed Concrete Pressure Pipe, AWWA Research Foundation, Denver, Colo, USA, 2001.

[34] F. H. Donaldson, T. J. Dilego, M. S. Higgins, E. A. Padewski, and J. S. Peluso, "Assessing and managing PCCP water transmission mains-Baltimore County, Maryland-a case study," in Proceedings of the Pipeline Division Specialty Conference, $\mathrm{p}$. 9, Chicago, Ill, USA, July-August 2006.

[35] F. H. Donaldson, R. S. Morrison, O. Singh, D. Lieu, J. Peluso, and B. Wright, "Baltimore's pilot water main inspection program becomes emergency rehab/replacement project," in Proceedings of the Pipelines: Advances and Experiences with Trenchless Pipeline Projects, p. 69, 2007.

[36] N. J. Carino, Stress Wave Propagation Methods in Handbook of Nondestructive Testing of Concrete, V. H. Malhotra and N. J. Carino Ed., CRC Press, Boca Raton, Fla, USA, 2004.

[37] M. Dingus, J. Haven, and R. Austin, Nondestructive, Noninvasive Assessment of Underground Pipelines, AWWA Research Foundation, Denver, Colo, USA, 2002.

[38] M. Eiswirth, C. Heske, L. S. Burn, and D. DeSilva, "New methods for water pipeline assessment," in Proceedings of the 2nd World Water Congress of the International Water Association, Berlin, Germany, October 2001.

[39] B. Karney, D. Khani, M. R. Halfawy, and O. Hunaidi, "A simulation study on using inverse transient analysis for leak detection in water distribution networks," Tech. Rep. NRCC50452, 2009.

[40] F. C. van der Kleij and M. J. Stephenson, " Acoustic logging - the bristol water experience," in Proceedings of The IWA Specialised Conference: Leakage Management-A Practical Approach, International Water Association, Lemesos, Cyprus, November 2002.
[41] M. Fantozzi, G. Di Chirico, and F. Tonolini, "Leak inspection on water pipelines by acoustic emission with cross-correlation method," in Proceedings of the AWWA Annual Conference and Exposition, San Antonio, Tex, USA, June 1993.

[42] H. V. Fuchs and R. Riehle, "Ten years of experience with leak detection by acoustic signal analysis," Applied Acoustics, vol. 33, no. 1, pp. 1-19, 1991.

[43] O. Hunaidi, W. Chu, A. Wang, and W. Guan, "Detecting leaks in plastic pipes," Journal of American Water Works Association, vol. 92, no. 2, pp. 82-94, 2000.

[44] O. Hunaidi, A. Wang, M. Bracken, T. Gambino, and C. Fricke, "Acoustic methods for locating leaks in municipal water pipe networks," in Proceedings of the International Conference on Water Demand Management, Dead Sea, Jordan, May-June 2004, http://irc.nrc-cnrc.gc.ca/ pubs/fulltext/nrcc47062/nrcc47062.pdf.

[45] Y. Gao, M. J. Brennan, P. F. Joseph, J. M. Muggleton, and O. Hunaidi, "A model of the correlation function of leak noise in buried plastic pipes," Journal of Sound and Vibration, vol. 277, no. 1-2, pp. 133-148, 2004.

[46] http://www.ppic.com/services/sahara.shtml.

[47] Water Environment Research Foundation, October 2009, http: / / www.werf.org/ AM/CustomSource/Downloads/uGetExecutiveSummary.cfm?FILE=ES - 01 - CTS - 7.pdf \& ContentFileID $=1960$.

[48] J. P. Vítkovský, A. R. Simpson, and M. F. Lambert, "Leak detection and calibration using transients and genetic algorithms," Journal of Water Resources Planning and Management, vol. 126, no. 4, pp. 262-265, 2000.

[49] J. G. Saldarriaga, D. A. A. Fuentes, and L. F. C. Galvis, "Implementation of the hydraulic transient and steady oscillatory flow with genetic algorithms for leakage detection in real water distribution networks," in Proceedings of the 8th Annual Water Distribution Systems Analysis Symposium, p. 52, Cincinnati, Ohio, USA, August 2006.

[50] M. Stephens, M. Lambert, A. Simpson, J. Vítkovsky, and J. Nixon, "Field tests for leakage, air pocket, and discrete blockage detection using inverse transient analysis in water distribution pipes," in Proceedings of the World Water and Environmetal Resources Congress: Critical Transitions in Water and Environmetal Resources Management, G. Sehlke, D. F. Hayes, and D. K. Stevens, Eds., vol. 138-147, pp. 4779-4788, ASCE, 2004.

[51] D. Covas, H. Ramos, A. Young, I. Graham, and C. Maksimovic, "Uncertainties of leak detection by means of hydraulic transients from the lab to the field," in Proceedings of the International Conference on Water Management for the 21st Century (CCWI '05), vol. 2, pp. 143-148, Exeter, UK, September 2005.

[52] A. F. Colombo, P. Lee, and B. W. Karney, "A selective literature review of transient-based leak detection methods," Journal of Hydro-Environment Research, vol. 2, no. 4, pp. 212-227, 2009.

[53] P. Mix, Introduction to Nondestructive Testing, A Training Guide, John Wiley \& Sons, Hoboken, NJ, USA, 2nd edition, 2005.

[54] J. B. Nestleroth and T. A. Bubenik, "Magnetic flux leakage (MFL) technology for natural gas pipeline inspection," Tech. Rep., The Gas Research Institute, February 1999, http://www.battelle.org/pipetechnology/mfl/mfl98main.html.

[55] S. Mukhopadhyay and G. P. Srivastava, "Characterization of metal loss defects from magnetic flux leakage signals with discrete wavelet transform," NDT \& E International, vol. 33, no. 1 , pp. 57-65, 2000. 
[56] M. Afzal and S. Udpa, "Advanced signal processing of magnetic flux leakage data obtained from seamless gas pipeline," NDT \& E International, vol. 35, no. 7, pp. 449-457, 2002.

[57] P. C. Porter, "Use of magnetic flux leakage (MFL) for the inspection of pipelines and storage tanks," in Nondestructive Evaluation of Aging Utilities, vol. 2454 of Proceedings of SPIE, pp. 172-184, Oakland, Calif, USA, May 1995.

[58] Y. Lijan, F. Haiying, and W. Yumei, "Research on intelligent pipeline magnetic flux leakage detector," in Proceedings of the 10th APCNDT Conference, Technology and Beyond, Brisbane, Australia, September 2001.

[59] R. Bickerstaff, M. Vaughn, and G. Stoker, "Review of Sensor Technologies for In-line Inspection of Natural Gas Pipelines," http://www.netl.doe.gov/technologies/oilgas/publications/Status_Assessments/71702.pdf.

[60] A. V. Joshi, L. Udpa, S. Udpa, and A. Tamburrino, "Adaptive wavelets for characterizing magnetic flux leakage signals from pipeline inspection," IEEE Transactions on Magnetics, vol. 40, no. 10, pp. 3168-3172, 2006.

[61] I. G. Vickridge and D. Leontidis, "Sewer surveys," in SewersRehabilitation and Construction, G. F. Read and I. G. Vickridge, Eds., vol. 1 of Repair and Renovation, pp. 84-102, Arnold London, London, UK, 1997.

[62] http://www.ge-energy.com/prod_serv/serv/pipeline/en/insp srvcs/crack_detection/ultrascan_cd/index.htm.

[63] J. L. Rose, J. J. Ditri, A. Pilarski, K. Rajana, and F. Carr, "A guided wave inspection technique for nuclear steam generator tubing," NDT \& E International, vol. 27, no. 6, pp. 307-310, 1994.

[64] J. L. Rose, D. Jiao, and J. Spanner Jr., "Ultrasonic guided wave NDE for piping," Materials Evaluation, vol. 54, no. 11, pp. 1310-1313, 1996.

[65] M. J. S. Lowe, D. N. Alleyne, and P. Cawley, "The mode conversion of a guided wave by a part-circumferential notch in a pipe," Journal of Applied Mechanics, Transactions, vol. 65, no. 3, pp. 649-656, 1998.

[66] D. N. Alleyne, B. Pavlakovic, M. J. S. Lowe, and P. Cawley, "Rapid long-range inspection of chemical plant pipework using guided waves," Insight, vol. 43, no. 2, pp. 93-96, 2001.

[67] R. Thompson, G. Alers, and M. Tennison, "Application of direct electromagnetic Lamb wave generation to gas pipeline inspection," in Proceedings of the IEEE Ultrasonic Symposium, pp. 91-94, New York, NY, USA, 1971.

[68] W. Mohr and P. Hoeller, "On inspection of thin-walled tubes for transverse and longitudinal flaws by guided ultrasonic waves," IEEE Transactions on Sonics and Ultrasonics, vol. 23, no. 5, pp. 369-374, 1976.

[69] D. N. Alleyne, M. J. S. Lowe, and P. Cawley, "The reflection of guided waves from circumferential notches in pipes," Journal of Applied Mechanics, Transactions ASME, vol. 65, no. 3, pp. 635-641, 1998.

[70] B. Pavlakovic, M. J. S. Lowe, D. Alleyne, and P. Cawley, "DISPERSE: a general purpose program for creating dispersion curves," in Reviews of Progress in Quantitative Nondestructive Evaluation, D. Thompson and D. Chimenti, Eds., vol. 16, pp. 185-192, Plenum, New York, NY, USA, 1997.

[71] A. Marzani, E. Viola, I. Bartoli, F. Lanza di Scalea, and P. Rizzo, "A semi-analytical finite element formulation for modeling stress wave propagation in axisymmetric damped waveguides," Journal of Sound and Vibration, vol. 318, no. 3, pp. 488-505, 2008.
[72] T. Hayashi, W. J. Song, and J. L. Rose, "Guided wave dispersion curves for a bar with an arbitrary cross-section, a rod and rail example," Ultrasonics, vol. 41, no. 3, pp. 175-183, 2003.

[73] J. N. Barshinger and J. L. Rose, "Guided wave propagation in an elastic hollow cylinder coated with a viscoelastic material," IEEE Transactions on Ultrasonics, Ferroelectrics, and Frequency Control, vol. 51, no. 11, pp. 1547-1556, 2004.

[74] J. Gauthier, V. Mustafa, A. Chabbaz, and D. R. Hay, "EMAT generation of horizontally polarized guided shear waves for ultrasonic pipe inspection," in Proceedings of the1st Pan American Conference for Nondestructive Testing (PACNDT '98), vol. 4, 1998.

[75] A. Demma, P. Cawley, M. Lowe, and A. G. Roosenbrand, "The reflection of the fundamental torsional mode from cracks and notches in pipes," Journal of the Acoustical Society of America, vol. 114, no. 2, pp. 611-625, 2003.

[76] V. M. N. Ledesma, E. P. Baruch, A. Demma, and M. J. S. Lowe, "Guided wave testing of an immersed gas pipeline," Materials Evaluation, vol. 67, no. 2, pp. 102-115, 2009.

[77] http://www.guided-ultrasonics.com/.

[78] S. A. Vinogradov, "Magnetostrictive transducer for torsional guided waves in pipes and plates," Materials Evaluation, vol. 67, no. 3, pp. 333-341, 2009.

[79] L.-Y. Sun, X.-D. Yang, and Y.-B. Li, "Research on transducer and frequency of ultrasonic guided waves in urban pipe inspection," in Proceedings of the 4th IEEE Conference on Industrial Electronics and Applications (ICIEA '09), pp. 27082711, 2009.

[80] N. Sarshar, M. R. Halfawy, and J. Hengmeechai, "Video processing techniques for assisted CCTV inspection and condition rating of sewers," in Proceedings of the Stormwater and Urban Water Systems Modeling Conference, Conceptual Modeling of Urban Water Systems, Monograph no. 17, pp. 129-149, Toronto, Canada, 2008.

[81] “Sewer Rehabilitation,” February 2010, http://www.sewerrehabilitation.com/.

[82] S. K. Sinha and M. A. Knight, "Intelligent system for condition monitoring of underground pipelines," Computer-Aided Civil and Infrastructure Engineering, vol. 19, no. 1, pp. 42-53, 2004.

[83] S. Iyer and S. K. Sinha, "Segmentation of pipe images for crack detection in buried sewers," Computer-Aided Civil and Infrastructure Engineering, vol. 21, no. 6, pp. 395-410, 2006.

[84] B. Teichgräber, J. Stemplewski, H. Althoff, and N. Elkmann, "Remote controlled inspection device for large sewers," Water Practice \& Technology, vol. 1, no. 4, 2006.

[85] T. Iseley, D. M. Abraham, and S. Gokhale, "Condition assessment of sewer systems," in Proceedings of the ASCE Conference on Trenchless Pipeline Projects, pp. 43-51, Boston, Mass, USA, June 1997.

[86] R. Wirahadikusumah, D. M. Abraham, T. Iseley, and R. K. Prasanth, "Assessment technologies for sewer system rehabilitation," Automation in Construction, vol. 7, no. 4, pp. 259-270, 1998.

[87] CEITEC, "Evaluation of SSET: the sewer scanner and evaluation technology," Tech. Rep. CERF Report 40551, ASCE, New York, NY, USA, 2001.

[88] M. Eiswirth, C. Frey, et al., "Sewer Assessment by multi-sensor system," in Proceedings of the 2nd World Water Congress of the International Water Association, Berlin, Germany, 2001.

[89] G. Campbell, K. Rogers, and J. Gilbert, "PIRAT-a system for quantitative sewer pipe assessment," in Proceedings of the International Conference on Trenchless Construction (No-Dig '95), Dresden, Germany, September 1995. 
[90] R. Kirkham, P. D. Kearney, K. J. Rogers, and J. Mashford, "PIRAT_a system for quantitative sewer pipe assessment," International Journal of Robotics Research, vol. 19, no. 11, pp. 1033-1053, 2000.

[91] D. Marlow, S. Heart, S. Burn, et al., "Condition assessment strategies and protocols for water and wastewater utility assets," Tech. Rep. 03-CTS-20CO, Water Environment Research Foundation, 2007. 

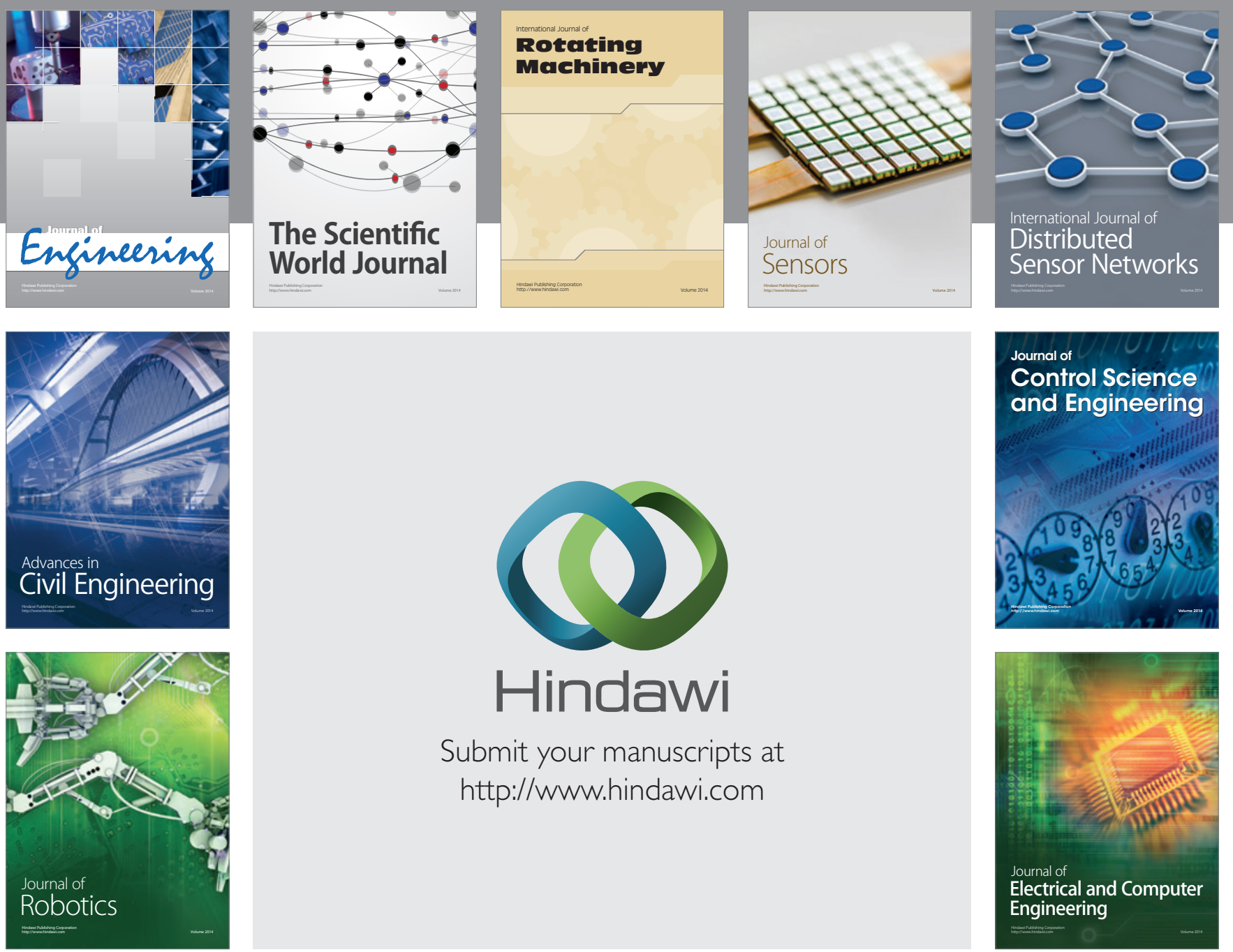

Submit your manuscripts at

http://www.hindawi.com
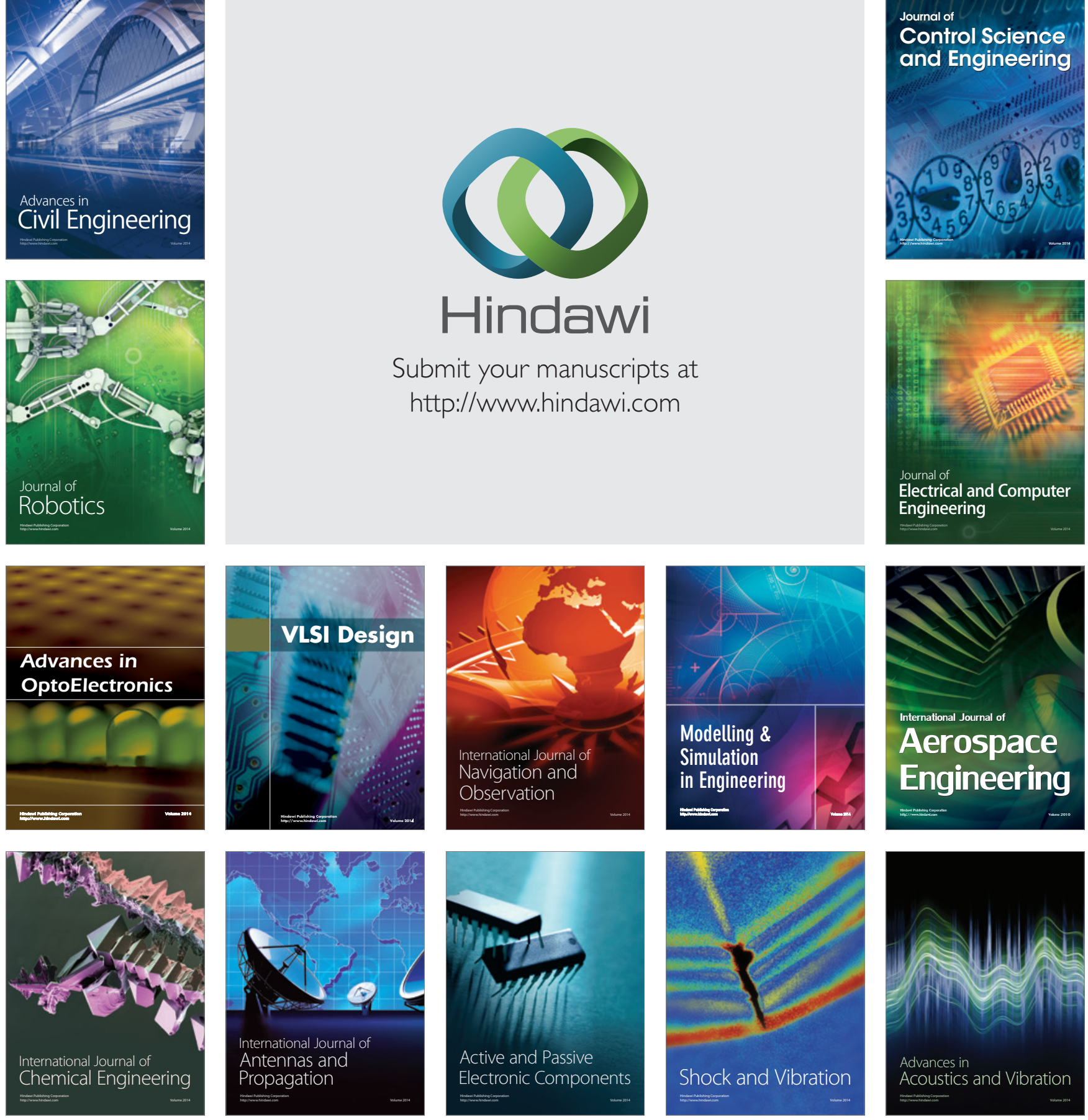